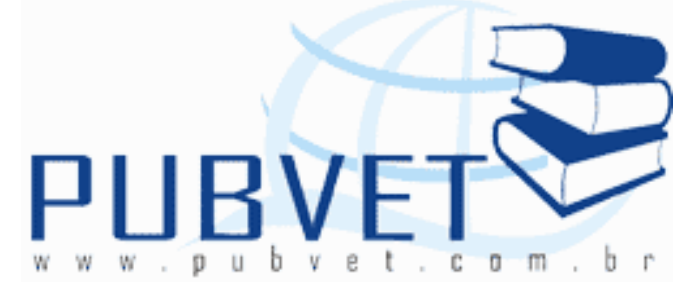

PUBVET, Publicações em Medicina Veterinária e Zootecnia.

\title{
Competição de clones de capim-elefante (Pennisetum purpureum) em Presidente Médici, Rondônia
}

\author{
Newton de Lucena Costa ${ }^{1}$, Claudio Ramalho Townsend ${ }^{2}$, João Avelar \\ Magalhães ${ }^{3}$, Ricardo Gomes de Araújo Pereira², Fabíola Helena dos Santos \\ Fogaça ${ }^{4}$ \\ ${ }^{1}$ Eng. Agrôn., D.Sc., Embrapa Roraima, Boa Vista, Roraima. \\ 2 Zootecnista, D.Sc., Embrapa Rondônia. Porto Velho, Rondônia. \\ ${ }^{3}$ Méd. Vet., D.Sc., Embrapa Meio Norte, Parnaíba, Piauí. \\ ${ }^{4}$ Zootecnista, D.Sc., Embrapa Meio Norte, Parnaíba, Piuaí.
}

\section{Resumo}

O desempenho agronômico de 19 clones e de uma cultivar de capim-elefante (Pennisetum purpureum) foi avaliado em ensaio conduzido em Presidente Médici, Rondônia. As maiores relações folha/colmo foram obtidas com os clones 92 F 198-8 (1,68), 92 F 79-2 $(1,45)$, 91 F 4-1 $(1,41)$ e 91 F 34-5 $(1,34)$. Durante o período chuvoso, os maiores rendimentos de MS foram obtidos pelos clones 92 F 79-2 (39,33 t/ha), 92 F 37-5 (34,97 t/ha) e 91 F 191 (34,15 t/ha). Em média, os rendimentos de forragem fornecidos por estes clones superaram em 33,$6 ; 18,8$ e $16,0 \%$, respectivamente, aqueles registrados pela cultivar Cameroon. Durante o período seco, os clones $91 \mathrm{~F}$ 2-5 (5,39 t/ha), 92 97-1 (5,23 t/ha) e CAC 262 (5,21 t/ha) apresentaram os 
maiores rendimentos de MS. Considerando-se os rendimentos de forragem e a relação folha/colmo, os clones mais promissores foram $92 \mathrm{~F}$ 79-2, $92 \mathrm{~F}$ 37-5, 91 F 19-1, 91 F 2-5, 92 F 97-1 e CAC 262.

Palavras-chave: perfilhamento, matéria seca, relação folha/colmo

\title{
Competition clones of elephant grass (Pennisetum purpureum) in Presidente Médici, Rondônia
}

\begin{abstract}
The agronomic performance of 19 clones and one cultivar of Pennisetum purpureum was assessed in a cutting trial carried out at Presidente Médici, Rondônia. The higher leaf/stem ratio were obtained with the clones $92 \mathrm{~F}$ 198-8 (1.68), 92 F 79-2 (1.45), 91 F 4-1 (1.41) and 91 F 34-5 (1.34). During the rainy season, the clones $92 \mathrm{~F} 79-2$ (39.33 t/ha), $92 \mathrm{~F} \mathrm{37-5} \mathrm{(34.97} \mathrm{t/ha)} \mathrm{and} 91$ F 19-1 (34.15 t/ha) provided higher dry matter yields. These clones produced increases of $33.6 ; 18.8$ and $16.0 \%$, over the control cultivar Cameroon, respectively. During the dry season, the clones more productive were $91 \mathrm{~F} \mathrm{2-5}$ (5.39 t/ha), 92 97-1 (5.23 t/ha) and CAC 262 (5.21 t/ha). In order to obtain greater forage yields and higher leaf/stem ratio, the clones more promising were 92 F 79-2, 92 F 37-5, 91 F 19-1, 91 F 2-5, 92 F 97-1 and CAC 262.
\end{abstract}

Keywords: dry matter, leaf/stem ratio, tillering

\section{Introdução}

Em Rondônia, as pastagens cultivadas constituem a principal fonte econômica para alimentação dos rebanhos. No entanto, devido às oscilações climáticas durante o ano, a produção de forragem apresenta flutuações estacionais, ou seja, abundância durante a estação chuvosa (outubro a maio) e déficit na estação seca (junho a setembro), o que implica em variações significativas dos índices de produtividade animal (MENDONÇA \& GONÇALVES, 1988; COSTA, 1996). 
A suplementação alimentar, durante o período de estiagem, torna-se imprescindível, visando amenizar o déficit nutricional dos rebanhos. A utilização de capineiras surge como uma das alternativas para assegurar um melhor padrão alimentar dos animais durante a época de escassez de forragem (COSTA \& GONÇALVES, 1988).

Com uma área cultivada superior a 200.000 hectares (OLIVEIRA \& SOUZA SOBRINHO, 2004), o capim-elefante (Pennisetum purpureum Schum.) está presente em todas as regiões do Brasil, devido ao fácil cultivo, adaptação a diferentes condições edafoclimáticas (DALL'AGNOL et al., 2004), elevada produção de forragem com bom valor nutritivo (COSTA et al., 2006; MAGALHÃES et al., 2006, 2009), boa palatabilidade, resistência a pragas e doenças, tendo sido utilizado para corte (COSTA et al., 2006; NASCIMENTO et al., 2008), silagem (NARCISO SOBRINHO, 1998; TOSI et al., 1999); pastejo (FREITAS et al., 2004; MEINERZ et al., 2011; MAGALHÃES et al., 2011), e mais recentemente indicado para agroenergia (FLORES et al., 2013). Em Rondônia essa forrageira é mais utilizada para a formação de capineiras, sendo as cultivares Napier e Cameroon as mais plantadas (MENDONÇA et al., 1979; GONÇALVES \& COSTA, 1986; COSTA \& GONÇALVES, 1988).

Por outro lado, a pecuária brasileira é sustentada por um número muito restrito de espécies forrageiras. Essa estreita base genética limita a capacidade de se elevarem os índices de produtividade do setor (STRAPASSON et al., 2000).

Assim, considerando-se a disponibilidade de novos clones de capimelefante, pré-selecionados em outras regiões do país, torna-se necessário avaliá-los sob as condições ecológicas locais, visando a seleção de cultivares mais produtivas e com melhor valor nutritivo que as tradicionais.

Neste trabalho avaliou-se o desempenho agronômico de clones de capim-elefante, visando selecionar os mais promissores para a formação de capineiras nas condições edafoclimáticas de Presidente Médici, Rondônia. 


\section{Material e Métodos}

O ensaio foi conduzido no Campo Experimental da Embrapa Rondônia, localizado no município de Presidente Médici (400 m de altitude, 10043' de latitude sul e $62^{\circ} 15^{\prime}$ de longitude oeste).

O clima da região é tropical úmido, do tipo Am, com precipitação média anual de $2.200 \mathrm{~mm}$, estação seca bem definida (junho a setembro), temperatura média de $24,9^{\circ} \mathrm{C}$ e umidade relativa do ar de $83 \%$. O solo da área experimental é um Podzólico Vermelho-Amarelo, textura média, fase floresta, com as seguintes características químicas: $\mathrm{pH}=5,9 ; \mathrm{P}=2 \mathrm{mg} / \mathrm{kg} ; \mathrm{Al}=0,0$ $\mathrm{cmol} / \mathrm{dm}^{3} ; \mathrm{Ca}+\mathrm{Mg}=4,8 \mathrm{cmol} / \mathrm{dm}^{3} ; \mathrm{K}=74 \mathrm{mg} / \mathrm{kg}$ e Matéria orgânica $=24,9$ $\mathrm{g} / \mathrm{kg}$.

O delineamento experimental foi em blocos casualizados com quatro repetições. Os tratamentos consistiram de 19 clones de capim-elefante (CNPGL 91 F 1-2, CNPGL 91 F 2-5, CNPGL 91 F 4-1, CNPGL 91 F 6-3, CNPGL 91 F 191, CNPGL 91 F 27-1, CNPGL 91 F 27-5, CNPGL 91 F 34-5, CNPGL 92 F 37-5, CNPGL 92 F 41-1, CNPGL 92 F 79-2, CNPGL 92 97-1, CNPGL 92 F 114-3, CNPGL 92 F 125-3, CNPGL 92 F 165-13, CNPGL 92 F 176-33, CNPGL 92 F 17833, CNPGL 92 F 198-8 e CAC 262), provenientes do Centro Nacional de Pesquisa de Gado de Leite (CNPGL-Embrapa Gado de Leite), além da cultivar Cameroon como testemunha local.

As parcelas eram compostas por cinco linhas com 5,0 $\mathrm{m}$ de comprimento, espaçadas de 1,0 m. A adubação de estabelecimento constou da aplicação de $30 \mathrm{t} / \mathrm{ha}$ de esterco bovino e de $50 \mathrm{~kg}$ de $\mathrm{P}_{2} \mathrm{O}_{5} / \mathrm{ha}$, sob a forma de superfosfato triplo.

Os parâmetros avaliados foram rendimento de matéria seca (MS), altura média das plantas, número de perfilhos $/ \mathrm{m}^{2}$ e relação folha/colmo. A avaliação da produção de MS foi realizada através de cortes mecânicos, a intervalos de 12 semanas, a uma altura de $30 \mathrm{~cm}$ acima do solo, exceto para o capimelefante cv. Anão, cortado a $20 \mathrm{~cm}$ acima do solo. 
COSTA, N.L. et al. Competição de clones de capim-elefante (Pennisetum purpureum) em Presidente Médici, Rondônia. PUBVET, Londrina, V. 7, N. 18, Ed. 241, Art. 1590, Setembro, 2013.

\section{Resultados e Discussão}

Durante o período chuvoso, os maiores rendimentos de MS foram registrados pelos clones $92 \mathrm{~F}$ 79-2 (39,33 t/ha), $92 \mathrm{~F}$ 37-5 (34,97 t/ha) e $91 \mathrm{~F}$ 19-1 (34,85 t/ha), os quais não diferiram entre si $(P>0,05)$ (Tabela 1). Em média, os rendimentos de forragem fornecidos por estes clones superaram em 33,$6 ; 18,8$ e $16,0 \%$, respectivamente, aqueles registrados pela cultivar Cameroon.

Tabela 1. Rendimento de matéria seca de clones de capim-elefante em Presidente Médici, Rondônia

\begin{tabular}{lcc}
\hline Clones & $\begin{array}{c}\text { Período chuvoso } \\
\text { (t/ha) }\end{array}$ & $\begin{array}{c}\text { Período seco }^{2} \\
(\mathrm{t} / \mathrm{ha})\end{array}$ \\
\hline CNPGL 91 F 1-2 & 29,65 & 4,54 \\
CNPGL 91 F 2-5 & 32,11 & 5,39 \\
CNPGL 91 F 4-1 & 29,22 & 3,00 \\
CNPGL 91 F 6-3 & 30,28 & 4,52 \\
CNPGL 91 F 19-1 & 34,85 & 2,11 \\
CNPGL 91 F 27-1 & 25,71 & 3,98 \\
CNPGL 91 F 27-5 & 25,92 & 3,67 \\
CNPGL 91 F 34-5 & 29,89 & 4,86 \\
CNPGL 92 F 37-5 & 34,97 & 2,02 \\
CNPGL 92 F 41-1 & 31,55 & 4,22 \\
CNPGL 92 F 79-2 & 39,33 & 2,51 \\
CNPGL 92 97-1 & 29,80 & 5,23 \\
CNPGL 92 F 114-3 & 27,45 & 3,12 \\
CNPGL 92 F 125-3 & 25,44 & 2,77 \\
CNPGL 92 F 165-13 & 26,91 & 2,56 \\
CNPGL 92 F 176-33 & 21,92 & 2,87 \\
CNPGL 92 F 178-33 & 25,10 & 1,86 \\
CNPGL 92 F 198-8 & 25,77 & 1,95 \\
CAC 262 & 27,46 & 5,21 \\
Cameroon & 29,44 & 4,60 \\
\hline Média & 29,10 & 3,54 \\
\hline DMS (Tukey 5\%) & & 0,87 \\
\hline 1- Soma de quatro cortes & & \\
2 - Um corte & & \\
3 - Híbridos interespecíficos de capim-elefante & \\
4 - Testemunha local & & \\
& & \\
\hline
\end{tabular}

Durante o período seco, os clones 91 F 2-5 (5,39 t/ha), 92 97-1 (5,23 t/ha) e CAC 262 (5,21 t/ha) apresentaram os maiores rendimentos de MS (Tabela 1). Em geral, os rendimentos de MS registrados com os clones mais produtivos são considerados satisfatórios, sendo superiores aos reportados por 
COSTA, N.L. et al. Competição de clones de capim-elefante (Pennisetum purpureum) em Presidente Médici, Rondônia. PUBVET, Londrina, V. 7, N. 18, Ed. 241, Art. 1590, Setembro, 2013.

MEIRELLES et al. (1997) e DAHER et al. (2000), avaliando os mesmos genótipos deste trabalho no Amapá e Rio de Janeiro, respectivamente.

As médias referentes à altura, relação folha/colmo e numero de perfilhos $/ \mathrm{m}^{2}$ dos clones de capim-elefante estão apresentadas na Tabela 2.

Tabela 2. Altura de plantas, relação folha/colmo, número de perfilhos $/ \mathrm{m}^{2}$ de clones de capim-elefante. Presidente Médici, Rondônia.

\begin{tabular}{|c|c|c|c|c|}
\hline \multirow{2}{*}{ Clones } & \multirow{2}{*}{$\begin{array}{c}\text { Altura } \\
(\mathrm{cm})\end{array}$} & \multirow{2}{*}{ Relação folha/colmo } & \multicolumn{2}{|c|}{ Perfilhos $/ \mathrm{m}^{2}$} \\
\hline & & & Basais & Aéreos \\
\hline CNPGL $91 \mathrm{~F}$ 1-2 & 2,80 & 0,69 & 78 & 0 \\
\hline CNPGL $91 \mathrm{~F} 2-5$ & 2,48 & 0,83 & 65 & 49 \\
\hline CNPGL 91 F 4-1 & 2,09 & 1,41 & 44 & 5 \\
\hline CNPGL $91 \mathrm{~F}$ 6-3 & 2,99 & 0,92 & 49 & 0 \\
\hline CNPGL 91 F 19-1 & 1,88 & 0,87 & 47 & 0 \\
\hline CNPGL 91 F 27-1 & 2,97 & 0,95 & 94 & 183 \\
\hline CNPGL 91 F 27-5 & 2,56 & 0,87 & 79 & 175 \\
\hline CNPGL 91 F 34-5 & 2,34 & 1,34 & 63 & 0 \\
\hline CNPGL 92 F 37-5 & 2,11 & 0,66 & 58 & 32 \\
\hline CNPGL 92 F 41-1 & 2,77 & 0,95 & 49 & 0 \\
\hline CNPGL 92 F 79-2 & 2,94 & 1,45 & 43 & 0 \\
\hline CNPGL 92 97-1 & 3,23 & 0,88 & 55 & 0 \\
\hline CNPGL 92 F 114-3 & 2,46 & 0,77 & 43 & 0 \\
\hline CNPGL 92 F $125-3$ & 2,45 & 0,89 & 49 & 0 \\
\hline CNPGL 92 F 165-13 & 2,78 & 1,12 & 50 & 45 \\
\hline CNPGL 92 F $176-33^{1}$ & 2,54 & 0,96 & 51 & 1 \\
\hline CNPGL 92 F $178-33^{1}$ & 2,34 & 0,74 & 48 & 78 \\
\hline CNPGL 92 F 198-8 & 1,18 & 1,68 & 63 & 67 \\
\hline CAC 262 & 2,43 & 0,99 & 54 & 45 \\
\hline Cameroon $^{2}$ & 2,08 & 0,93 & 45 & 0 \\
\hline Média & 2,47 & 0,99 & 56,35 & 34 \\
\hline
\end{tabular}

1 - Híbridos interespecíficos de capim-elefante $x$ milheto

2 - Testemunha local

As maiores alturas de plantas foram verificadas com os clones $92 \mathrm{~F}$ 97-1 (3,23 m), 91 F 6-3 (2,99 m), 91 F27-1 (2,97 m), 92 F 79-2 (2,94 m) (Tabela 2). Aparentemente não houve uma relação direta entre altura das plantas e número de perfilhos com o rendimento de forragem. Observou-se grande variabilidade quanto à capacidade de perfilhamento dos genótipos, embora nem sempre os acessos com maior número de perfilhos proporcionassem maior cobertura do solo ou maior produtividade de forragem. O número de perfilhos $/ \mathrm{m}^{2}$ variou entre 43 e 94 e, 0 e 183, respectivamente para os basais e aéreos, sendo os maiores valores registrados com os clones 91 F 27-1 (183 
perfilhos $/ \mathrm{m}^{2}$ ) e 91 F 27-5 (175 perfilhos $/ \mathrm{m}^{2}$ ) (Tabela 2). Resultados semelhantes foram reportados por MEIRELLES et al. (1997) avaliando os mesmos clones nos cerrados do Amapá, porém superiores aos relatados por FERNANDES et al. (2002) que encontraram 30 e 115 perfilhos $/ \mathrm{m}^{2}$, para os clones 91 F 27-1 e 91 F 27-5, respectivamente, na região do Distrito Federal.

A relação folha/colmo ( $F / C)$ é um parâmetro de grande destaque sob o ponto de vista nutritivo e para o manejo das gramíneas forrageiras. Das variações de peso das frações folha e colmo, resultam diferenças entre as gramíneas forrageiras, em que a alta relação F/C representa forragem de maior teor de proteína, minerais, digestibilidade e consumo. As maiores relações F/C foram obtidas com os clones 92 F 198-8 (1,68), 92 F 79-2 (1,45), 91 F 4-1 $(1,41)$ e 91 F 34-5 $(1,34)$. Esses resultados superam o limite critico de relação F/C indicado de 1,0 por PINTO et al. (1994) para gramíneas tropicais.

Com relação à incidência de doenças e pragas, notadamente da cigarrinha-das-pastagens (Deois incompleta, D. flavopicta e Notozulia entreriana), não foi registrada nenhuma ocorrência. Em Teresina, Piauí, trabalhando com 10 variedades de capim-elefante oriundos do programa de melhoramento genético da Embrapa Gado de Leite (CNPGL 91-06-2, CNPGL 91-11-2, CNPGL 91-25-1, CNPGL 91-27-5, CNPGL 92-101-2, CNPGL 92-38-2, CNPGL 92-41-1, CNPGL 92-66-3, CNPGL 94-07-2 e CNPGL 96-25-1) e duas testemunhas locais (Napier comum e elefante de Altos), ITALIANO et al. (2006) registraram a presença de cigarrinha-das-pastagens em todos os materiais, variando entre 4,8 (Napier) e 16,9 ninfas/planta (CNPGL 91-11-2), porém, não houve diferenças estatísticas devido ao elevado coeficiente de variação.

\section{Conclusões}

Os resultados obtidos evidenciaram um desempenho agronômico diferenciado entre os clones avaliados. Considerando-se os rendimentos de MS e a sua distribuição estacional e a relação folha/colmo, os clones mais 
COSTA, N.L. et al. Competição de clones de capim-elefante (Pennisetum purpureum) em Presidente Médici, Rondônia. PUBVET, Londrina, V. 7, N. 18, Ed. 241, Art. 1590, Setembro, 2013.

promissores para a formação de capineiras nas condições ecológicas de Presidente Médici (RO) foram 92 F 79-2, 92 F 37-5, 91 F 19-1, 91 F 2-5, 92 F 97-1 e CAC 262, os quais apresentaram maior potencial forrageiro que as cultivares tradicionalmente utilizadas na região.

\section{Referências Bibliográficas}

COSTA, N. de L. Programa de pesquisa com pastagens em Rondônia 1975/1995. Porto Velho: EMBRAPA-CPAF Rondônia, 1996. 34p. (Documentos, 32).

COSTA, N. de L.; GONÇALVES, C.A. Épocas de vedação e utilização de capineiras de capimelefante em Porto Velho, Rondônia. Pasturas Tropicales, v.10, n.2, p.34-37, 1988.

COSTA, N. de L.; MAGALHÃES, J. A. ; A.; TOWNSEND, C.R. Efeito de regimes de cortes sobre a produção e qualidade da forragem de capim-elefante (Pennisetum purpureum cv. Mott). Revista Científica Rural, v.11, p.28-33, 2006.

DAHER, R. F.; VÁZQUEZ, H. M.; PEREIRA, A. V. Introdução e avaliação de clones de capimelefante (Pennisetum purpureum, Schum.) em Campos dos Goytacazes, RJ. Revista Brasileira de Zootecnia, v.29, n.5, p.1296-1301, 2000.

DALL'AGNOL, M.; SCHEFFER-BASSO, S.M.; NASCIMENTO, J.A.L.; SILVEIRA, C.A.M.; FISCHER, R.G. Produção de forragem de capim elefante sob clima frio. Curva de crescimento e valor nutritivo. Revista Brasileira de Zootecnia, v. 33 n.5 p. 1110-2004.

FERNANDES, F.D.; PEREIRA, A.V.; LÊDO, F.J.S.; VILELA, L.; CARVALHO, M.A. Avaliação agronômica de clones de capim-elefante no Distrito Federal. Planaltina: EMBRAPA, 2002. 15p. (Boletim de Pesquisa e Desenvolvimento, 41).

FLORES, R.A.; URQUIAGA, S.; ALVES, B.J.R.; COLIER, L.S.; ZANETTI, J.B.; PRADO, R.M. Nitrogênio e idade de corte na qualidade da biomassa de capim-elefante para fins agroenergéticos cultivado em Latossolo. Semina: Ciências Agrárias, Londrina, v. 34, n. 1, p. 127-136, 2013.

FREITAS, E.V.; LIRA, M.A.; DUBEUX JÚNIOR, J.C.B.; SANTOS, M.V.F.; MELLO, A.C.L.; TABOSA, J.N.; FARIAS, I. Características produtivas e qualitativas de clones de capim-elefante (Pennisetum purpureum Schum.) avaliados sob pastejo na Zona da Mata de Pernambuco. Acta Scientiarum. Animal Sciences, v.26, n.2, p.251-257, 2004.

GONÇALVES, C.A.; COSTA, N. de L. Altura e frequência de corte de capim-elefante (Pennisetum purpureum Schum. cv. Cameroon) em Porto Velho-RO. Porto Velho: EMBRAPA-UEPAE Porto Velho, 1986. 8p. (Comunicado Técnico, 40).

ITALIANO, E.C.; PEREIRA, A.V.; LEDO, F.J.S. Comportamento produtivo de genótipos de capim-elefante (Pennisetum purpureum) para corte na região Meio-Norte do Brasil. Revista Científica de Produção Animal, v.8, n.2, p.47-55, 2006.

MAGALHÃES, J.A.; LOPES, E.A.; RODRIGUES, B.H.N; ; COSTA, N. de L.; BARROS, N.N.; MATTEI, D.A. Influência da adubação nitrogenada e da idade de corte sobre 0 rendimento forrageiro do capim-elefante. Revista Ciência Agronômica, v.37, p.91-96, 2006.

MAGALHÃES, J.A.; RODRIGUES, B.H.N.; ARAÚJO NETTO, R.B. de; COSTA, N. de L.; BEZERRA, E.E.; SANTOS, J.M. dos; POMPEU, R.C.F.F. Produção de leite com vacas mestiças em capimelefante. Pubvet, v.5, n.35, Art\#1226, 2011. 
MAGALHÃES, J.A.; RODRIGUES, B.H.N.; CARNEIRO, M.S.S.; ANDRADE, A.C.; COSTA, N. de L.; PINTO, M.S.C.; MOCHEL FILHO, W.J.E. Influência da adubação nitrogenada e idade de corte sobre os teores de proteína bruta e fibra em detergente neutro de três cultivares de capim-elefante. Revista Electrónica de Veterinaria, v.10, p.35-43, 2009.

MEINERZ, G.R. ; OLIVO, C.J. ; AGNOLIN, C.A.; MORAES, R.S.; DULLIUS, A. P.; Mombach, G.; FOLETTO, V. ; MACHADO, P.R. Produção e valor nutritivo da forragem do capim-elefante em dois sistemas de produção. Revista Brasileira de Zootecnia, v.40, p.2673-2680, 2011.

MEIRELLES, P.R. de L.; PEREIRA, A.V.; MOCHIUTTI, S. Avaliação e seleção de capim-elefante (Pennisetum purpureum Schum.) no cerrado do Amapá. In: REUNIÃO ANUAL DA SOCIEDADE BRASILEIRA DE ZOOTECNIA, 34., 1997, Juiz de Fora. Anais... Juiz de Fora: SBZ, 1997, p.9799.

MENDONÇA, J.F.B.; GONÇALVES, C.A. Comportamento produtivo de 12 gramíneas forrageiras de corte em diferentes níveis de adubação fosfatada num solo de Porto Velho, RO. Porto Velho: EMBRAPA-UEPAE Porto Velho, 1988. 14p. (Boletim de Pesquisa, 8).

MENDONÇA, J.F.B.; GONÇALVES, C.A.; CURI, W.J. Introdução e avaliação de gramíneas forrageiras de corte. Porto Velho: EMBRAPA-UEPAE Porto Velho, 1979. 22p. (Comunicado Técnico, 7).

NARCISO SOBRINHO, J.N. Silagem de capim elefante (Pennisetum purpureum Schum.), em três estádios de maturidade, submetido ao emurchecimento. Boletim de Indústria Animal, v.55, n.2, p.113-125, 1998.

NASCIMENTO, I. S.; MONKS, P. L.; SILVA, J. B. Efeito de cortes outonais e hibernais sobre o desempenho produtivo do capim elefante cv. Cameroon. Revista Brasileira de Ciências Agrárias, v.3, n.2, p.191-196, 2008.

OLIVEIRA, J. S.; SOUZA SOBRINHO, F. de. Cultivares de milho para silagem: resultados das safras 2002/2003 e 2003/2004. Juiz de Fora: Embrapa Gado de Leite, 2004. 21p. (Circular Técnica, 81).

PINTO, J.C.; GOMIDE, J.A.; MAESTRI, M. Produção de MS e relação folha/caule de gramíneas forrageiras tropicais, cultivadas em vasos, com duas doses de nitrogênio. Revista da Sociedade Brasileira de Zootecnia, v.23, n.3, p. 313-326, 1994.

STRAPASSON, E.; VENCOVSKY, R.; BATISTA, L.A.R. Seleção de descritores na caracterização de germoplasma de Paspalum sp. por meio de componentes principais. Revista da Sociedade Brasileira de Zootecnia, v.29, n.2, p,373-381, 2000.

TOSI, P.; MATTOS, W. R.; TOSI, H.; JOBIM, C.C.; LAVEZZO, W. Avaliação do capim-elefante (Pennisetum purpureum Schum.) cultivar Taiwan A-148, ensilado com diferentes técnicas de redução de umidade. Revista Brasileira de Zootecnia, v.28, n.5, p.947-954, 1999. 